\title{
Horizontal Earth Movement in the Baldwin Hills, Los Angeles Area
}

\author{
Ira H. Alexander \\ Survey Division, Department of County Engineer \\ Los Angeles County, California
}

\begin{abstract}
Since subsidence is often accompanied by horizontal earth movements, an area undergoing vertical surveillance can be checked for such horizontal movement by triangulation if prior geodetic positions are known within the region. Triangulation station Baldwin Aux., whose position was determined by the 1934 Cooperative Control Survey of the metropolitan Los Angeles area, and which falls within a known area of subsidence, was reobserved. By using as control some of the other original 1933 stations which were external to the subsidence area, the adjustment resulting from observations on these points showed a horizontal movement of greater than 2 feet in 27 years. From secondary triangulation emanating from the 1961 position of Baldwin Aux., the horizontal movement of other previously positioned points was determined, and resulting movement vectors were computed. Recommendations are made for a systematic program of reobservations to be made in the future. This program should follow the pattern of observing procedure and reduction that has been used so successfully in the past in the Terminal Island-Long Beach subsidence area.
\end{abstract}

The successful application of triangulation to the study of horizontal earth movement in California goes back almost to the beginning of this century. Because of the heavy prevalence of signs of superficial earth movement, seismic activity, and vertical subsidence, the U. S. Coast and Geodetic Survey examined the comparisons of positions of many of their triangulation stations over definite time intervals to see whether they were within the expected discrepancies of triangulation reobservations or were attributable to actual horizontal earth movement.

The results of these studies were embodied in a series of publications by that organization [Hayford and Baldwin, 1907; Bowie, 1924, 1928]. In the last, a complete summary and résumé of all such past work in California appeared.

The general statement that horizontal earth movement of the largest magnitude occurs near major fault lines seems to have been borne out by the results, the magnitudes diminishing at stations farther away. To the writer's knowledge, no critique has appeared in the literature to date which covers any analytic form of this lessening of movement with distance. In these studies, the best method of determining earth movement in a seismic region was held to be by means of short arcs of first-order triangulation extending across the fault zone.
Since the appearance of Bowie's summary, the concept of the best type of survey to show these movements has changed to favor the method of area triangulation. Whitten [1949] presented considerable evidence to show this, especially when orientation is checked by the use of astronomic azimuths on long lines crossing the fault.

A new method of analysis of triangulation reobservations for horizontal earth movement was devised by Whitten [1960]. This method makes use of the differential movement to be expected when changes are noted in the direction of a previously observed line. It was emphasized that this technique supplements, rather than replaces, the classical methods of reobservation.

A most complete summary of the techniques used to determine displacement of terrain and deformation in structures by geodetic methods was given recently by Kobold [1961]. He presented the results of applying such techniques to the determination of absolute movement differentiation to intensive areas, i.e. engineering structures such as dams and tunnels, with examples chosen primarily from current European practice.

By most of the methods referred to above, many data have been obtained and analyzed for the Terminal Island-Long Beach subsidence area. Berbower [1959], in discussing more general engineering aspects of this particular sub- 


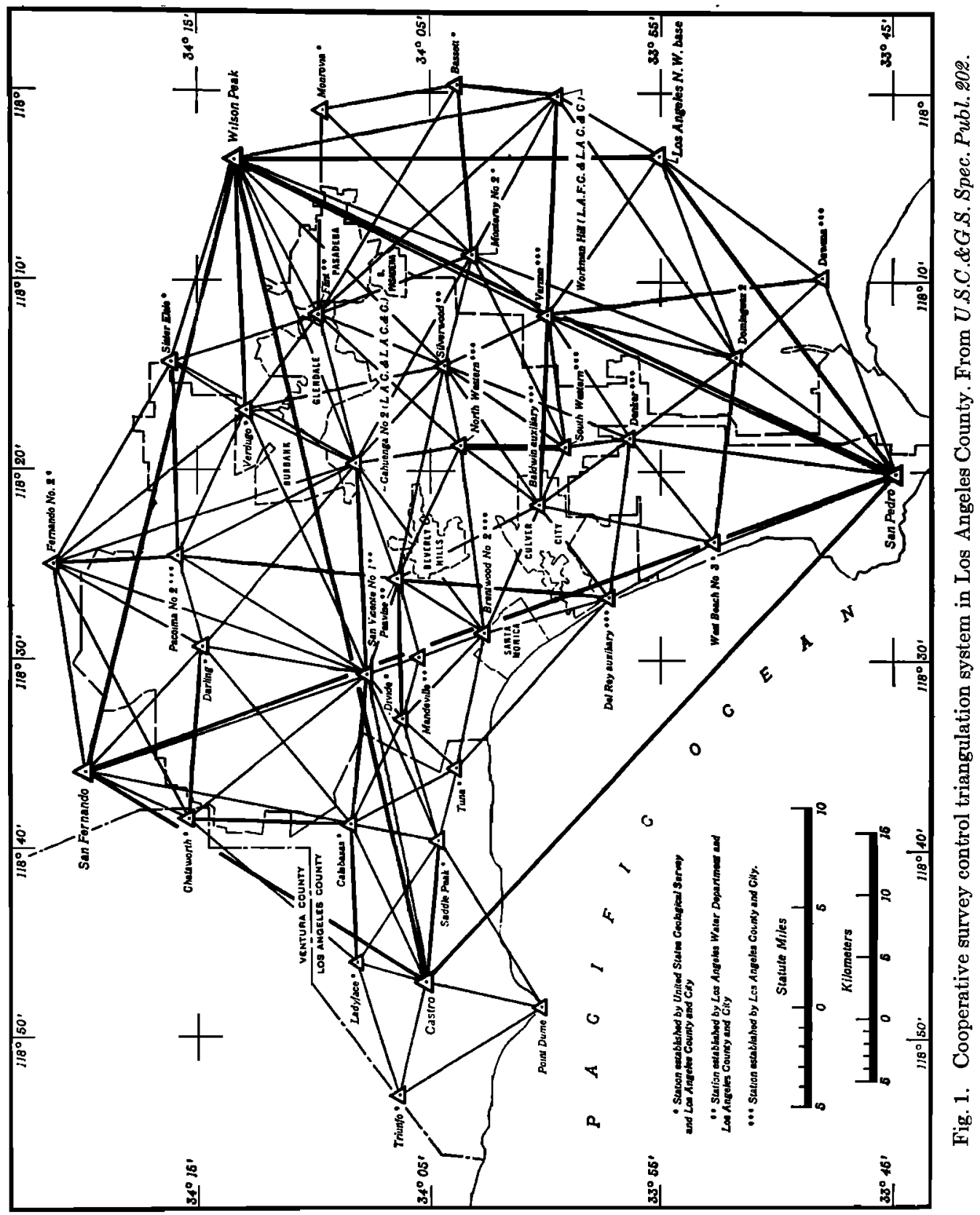




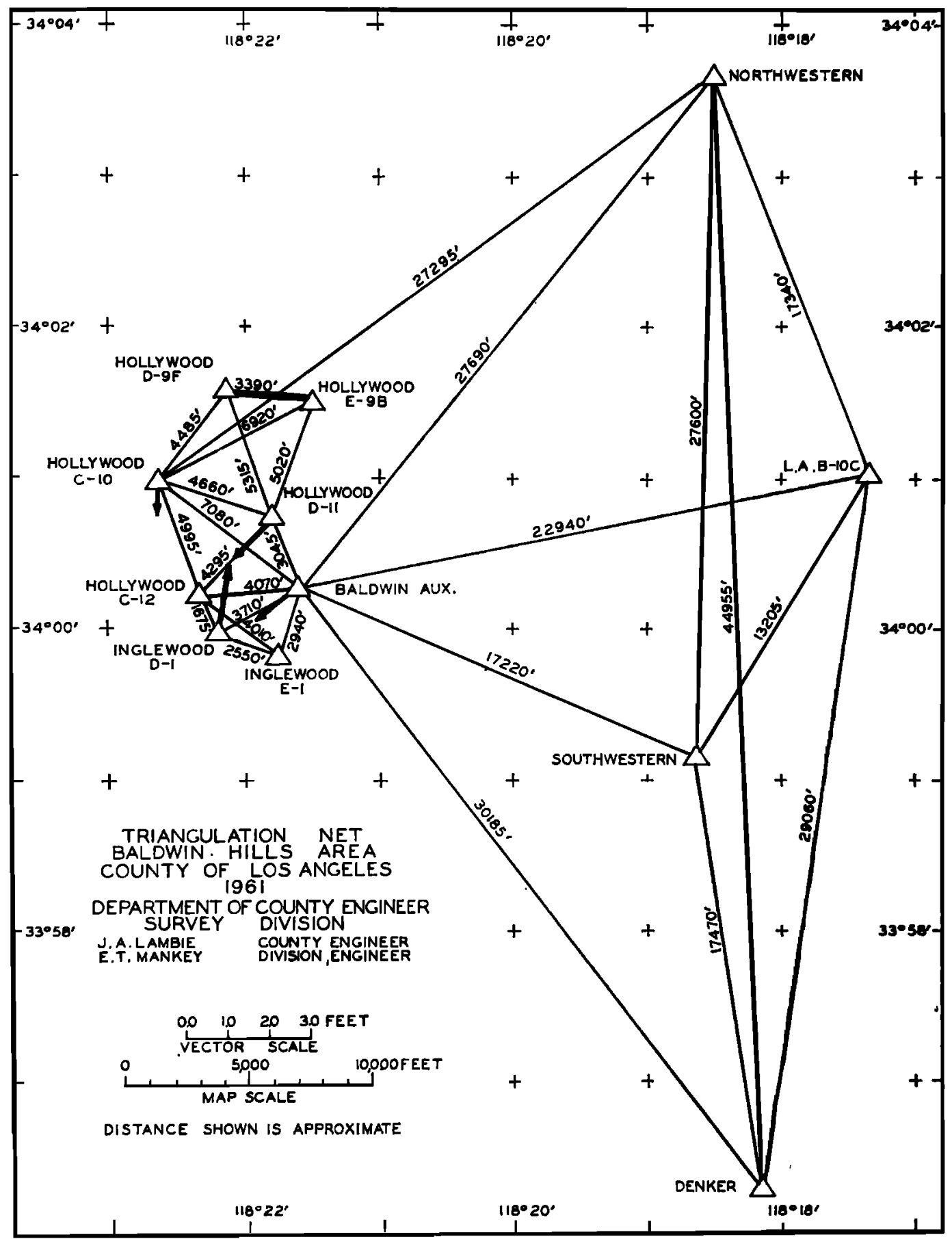

Fig. 2. Triangulation nets used for 1961 observations, and displacement vectors, Baldwin Hills area, Los Angeles County. 
TABLE 1. Triangulation Statistics

\begin{tabular}{|c|c|c|}
\hline Field Work & $\begin{array}{l}\text { Primary } \\
\text { Net }\end{array}$ & $\begin{array}{c}\text { Secondary } \\
\text { Net }\end{array}$ \\
\hline New stations established & 1 & 7 \\
\hline Total stations occupied & $\mathbf{5}$ & 10 \\
\hline Total directions observed & 20 & 36 \\
\hline New directions & 8 & 34 \\
\hline Triangles & & \\
\hline $\begin{array}{l}\text { Total number of triangles } \\
\text { Ayerage closure of }\end{array}$ & 6 & 13 \\
\hline triangle, sec* & 1.18 & 1.60 \\
\hline $\begin{array}{l}\text { Maximum closure of } \\
\text { triangles, see* }\end{array}$ & 2.26 & 3.71 \\
\hline Triangles with plus & & \\
\hline $\begin{array}{l}\text { closures } \\
\text { Triangles with minus }\end{array}$ & 1 & 5 \\
\hline closures & 5 & 7 (one flat) \\
\hline $\begin{array}{l}\text { Mean error of an angle, } \\
\text { sec }\end{array}$ & 0.78 & 1.16 \\
\hline $\begin{array}{l}\text { Concluded triangles } \\
\text { Condition Equations }\end{array}$ & $\mathbf{0}$ & 0 \\
\hline Angle & 3 & 10 \\
\hline Side & 0 & 3 \\
\hline Length & 2 & 1 \\
\hline Total & 5 & 14 \\
\hline Average correction, sec & 0.44 & 0.43 \\
\hline Maximum correction, sec & 0.75 & 1.58 \\
\hline $\begin{array}{l}\text { Probable error of } \\
\text { observed direction, sec }\end{array}$ & 0.42 & 0.60 \\
\hline
\end{tabular}

* Because of poor visibility and lack of time, it was necessary to accept closures that were not within first-order standards.

sidence problem, showed the results of triangulation reobservations up to 1954 . Application of these data to geology was presented by Gilluly and Grant [1949]. The Department of County Engineer, Los Angeles County, the Department of Public Works, City of Los Angeles, the Long Beach Harbor Department, and the City Engineer, City of Long Beach, have cooperatively studied this area since 1937. The last year of reobservation by this group was 1958 . It is anticipated that in 1962 the program will be resumed.

Because of the general acceptance of the results of the Terminal Island-Long Beach surveys, other areas in which subsidence was superficially evident were put under intensive study. One such was the Baldwin Hills region, an area where vertical subsidence had been noted for many years. There, the Los Angeles Department of Water and Power had planned and built a large reservoir. A thorough and continuous series of reports prepared under the direction of Hayes [1943, 1947, 1951, 1955, 1959] show the considerable leveling done to record vertical movement in that area. A few traverse ties were made, but, because they stayed within the area, only relative horizontal movement was disclosed.

By 1960 sufficient building activity in the area had made it imperative that horizontal movement, as well as vertical subsidence, be determined. Various superficial evidences of movement, such as cracks and slipping, implied that such movement was continuing.

The Survey Division of the Department of County Engineer made a reconnaissance of the area and selected station Baldwin Aux. to be the key point of the study. Not only did it lie well within the area but its history was that of possessing a classic geodetic pedigree-namely, its position had been determined by first-order triangulation methods almost 27 years before, when the entire Los Angeles coastal plain was included in the large cooperative survey project performed by Los Angeles County, Los Angeles City, and the Los Angeles Department of Water and Power. This project, referred to as the 38 Station Net, provided valuable control to the Los Angeles area. By referring to the sketch (Fig. 1) it may be seen that Northwestern, Southwestern, and Denker were all stations which were intervisible with Baldwin Aux.

Northwestern is at the top of a ten-story office building in the vicinity of Wilshire Boulevard and Western Avenue; Southwestern is at the top of a large 310-foot-high gas holder at Western and Slauson avenues. They are the termini of a taped base line approximately 28,000 feet long. The probable error of the measured base in 1934 was 1 part in 2,900,000. The probable error of the projected base was 1 part in $1,520,000$. As will be shown in subsequent discussion, good use was made of known data concerning this length.

Before the triangulation scheme is discussed, a short review of some of the desirable criteria for triangulation comparisons to ensure stability of external stations is in order. As expressed by Whitten [1960]:

The problem of measuring small horizontal movements on the surface of the earth in areas of seismic activity has generally been solved by re- 
TABLE 2. Tabulation of Horizontal Earth Movement

Displacement Vector Period of

Station Bearing $\begin{gathered}\text { Distance, } \\ \mathrm{ft}\end{gathered} \begin{gathered}\begin{array}{c}\text { Com- } \\ \text { parison }\end{array} \\ \text { f }\end{gathered}$

\begin{tabular}{lllll}
$\begin{array}{l}\text { Hollywood } \\
\text { C-10 }\end{array}$ & S & $7^{\circ} 16^{\prime} \mathrm{W}$ & 0.95 & $1936-1961$ \\
$\begin{array}{l}\text { Hollywood } \\
\text { D-11 }\end{array}$ & S $49^{\circ} 13^{\prime} \mathrm{W}$ & 1.64 & $1936-1961$ \\
$\begin{array}{l}\text { Inglewood D-1 } \\
\text { Baldwin Aux. }\end{array}$ & $\mathrm{N} 11^{\circ} 33^{\prime} \mathrm{E}$ & 1.85 & $1936-1961$ \\
\hline
\end{tabular}

TABLE 3. Comparison of Adjusted Spherical Angles

\begin{tabular}{|c|c|c|}
\hline Station & Adjusted Spherical Angles & $\begin{array}{l}\text { Differ- } \\
\text { ence }\end{array}$ \\
\hline \multirow{4}{*}{$\begin{array}{l}\text { Baldwin } \\
\text { Aux. } \\
\text { North- } \\
\text { western } \\
\text { South- } \\
\text { western }\end{array}$} & 1934 & \\
\hline & $75^{\circ} 18^{\prime} 23.50^{\prime \prime} 75^{\circ} 17^{\prime} 55.90^{\prime \prime}$ & $-27.60^{\prime \prime}$ \\
\hline & $37^{\circ} 06^{\prime} 50.75^{\prime \prime} \quad 37^{\circ} 06^{\prime} 58.35^{\prime \prime}$ & $+7.60^{\prime \prime}$ \\
\hline & $67^{\circ} 34^{\prime} 45.85^{\prime \prime} 67^{\circ} 35^{\prime} 05.85^{\prime \prime}$ & $+20.00^{\prime \prime}$ \\
\hline
\end{tabular}

observing a triangulation network. If there have been changes, the difference in the observations will indicate the magnitude of the movement. Because of the complexity and interlocking characteristics of a triangulation network, the usual practice for calculating these shifts of position has been to compute geographic coordinates of the points for each set of observations and then to compare the coordinates. There is always the chance that limitations imposed by inevitable errors of observation or weaknesses in the network itself may produce accumulated effects that exceed any conceivable ground movement. Also a stable base line must always be available as a reference for the network. Any small shift in one of the reference points can product fictitious shifts of position.

To subject a base line to geodetic scrutiny calls for (1) a check on length and (2) a check on rotation. To check the rotation of the line Northwestern-Southwestern, the directions to Northwestern and Denker were reobserved from Southwestern and the resultant observed angle differed by only 0.85 second from the record angle resulting from the 1934 adjustment. This is well within the limits of instrumental error, and so rotational stability of the three points, Northwestern, Southwestern, and Denker, is implied in the simple use of the term.
The actual adjusting was done in two parts; the first resulted in a 1961 position for station Baldwin Aux.; the second, holding this 1961 position, resulted in 1961 positions for several other points for which prior positions existed. Figure 2 shows the combined 1961 triangulation scheme.

Shown in Table 1 are the triangulation statistics for the two adjustments.

Table 2 consists of triangulation stations for which prior positions existed, and their movement vectors result from comparisons of their old positions with those determined in 1961 .

In the first adjustment the record positions for Northwestern, Southwestern, Denker, and L.A. B-10C were held, and Baldwin Aux. was treated as a new station. Five condition equations were involved, and two of them, being length conditions, provided a means of checking some of the record lengths. The first of these length conditions had a strength of figure of 34.3, and provided a closure between the base line Northwestern-Southwestern and the record line Southwestern-Denker of 1 part in 477,250 before the least-squares adjustment; after satisfaction of angle conditions this was reduced to 1 part in 310,000 . This implies fixity of length for the line Northwestern-Southwestern. The second of these length conditions used as fixed lines Northwestern-L.A. B-10C and L.A. B-10CSouthwestern. Here the unadjusted closure was 1 part in 162,050; after meeting angle conditions this dropped to 1 part in 111,000 . Strength of figure was 13.2.

The apparent displacement of 2.21 feet for the 1961 position of Baldwin Aux., compared with that determined in 1934, involves the basic triangle defined by the stations Baldwin Aux., Northwestern, and Southwestern. The misclosure of this triangle in 1934 was 1.76 seconds; in 1961 it was 0.57 second. The tabulated adjusted spherical angles at these stations are shown in Table 3.

By use of the approximate relationship that a displacement of 1 foot in 40 miles involves an angular change of 1 second, and taking the lengths in this triangle to be of the magnitude of 5 miles, a displacement of 2.21 feet implies angular changes of the order of 17 seconds. Upon noting the much smaller angular quantities involved in the adjustment of the triangulation, we conclude that the bulk of this angular change 
is due to actual movement of the point, and not to the small discrepancy that normally could be expected in the observation of a triangulation net.

Another method of examination of this derived displacement is to consider the expression for the square of the probable error of the logarithm of a side of a figure.

$$
L^{2}=4 / 3 d^{2} R
$$

where $R$ is the strength of figure, $d$ is the probable error of an observed direction, in seconds, and $L$ is the probable error that would occur in the sixth decimal place of the logarithm of a side of a figure. No error is assumed in the starting base.

As is known, $R$ is independent of the accuracy with which the angles are measured; it depends entirely upon the figure chosen. Applying this to the first length condition mentioned previously, we find that $L=2.84$ for $R=34.3$ and $d=0.42 \mathrm{sec}$. Dividing by the modulus of common logarithms, $M=0.4343$, gives 1 part in 153,000 as the probable error of a side in this length condition. Taking the longest side, Denker-Baldwin Aux, gives a probable error of about 0.20 foot. Since this side was used in computing the 1961 position of Baldwin Aux., we have another estimate of the size of discrepancy that is attributable to inherent errors of this triangulation. It should be emphasized that the assumption of no error at the starting base is, in some instances, of sufficient weakness to warrant caution in the conclusions derived therefrom.

For the secondary net an invar taped base was set between stations Hollywood D-9E and Hollywood E-9B to provide a more usable reference length for future reobservations and to strengthen the triangulation. The record positions of Northwestern and Baldwin Aux. (1961) were held, and Hollywood C-10, C-12, E-9F, D-11, and E-9B and Inglewood D-1 and E-1 were treated as new stations. Fourteen condition equations were involved. The length condition provided a closure between the base line Hollywood D-9B-Hollywood E-9B and the record line Baldwin Aux. (1961)-Northwestern. Although the distance angle at Baldwin Aux. is weak, the strength of figure is 54, which is acceptable for first-order triangulation. Agreement between these two lines was 1 part in 330,000 before adjustment; after satisfaction of angle and side conditions, this was reduced considerably-to 1 part in 71,000-but it still is of sufficient magnitude to disclose weaknesses in length agreement. Since first-order methods and equipment were used and conformity to checks of the conditions of rotation and fixity of length was maintained, a movement of more than 2 feet may definitely be attributed to horizontal earth movement. The fact that all the movement vectors had quite diverse directions implies, through the condition of nonparallelism, that the movement was in the Baldwin Hills area and not in the external area containing the outside control points.

In the metropolitan area of Los Angeles the difficulties of geodetic field work have increased with time. Poor visibility (affecting time of reobservation and triangle closures), new obstructions to lines of sight (necessitating the use of unusually complex, eccentric stations), and destruction of existing primary triangulation stations are the leading reasons for exercising care in the selection of points for reobservation schemes.

With the setting of a first set of movement vectors for this area, means now exist for the continuance of observation of earth movements. These include:

1. A systematic releveling across and around the area. (This has been done by several agencies but was not discussed in this paper.)

2. A pattern of precise traverse ties to determine relative movements within the subsidence area.

3. A repetition of the basic reobservations from the primary triangulation stations external to the area. To ensure a continuing effective program, intensive double-checking of reference and tie points will be necessary.

4. Orientation control, if possible, by means of Laplace azimuths.

Acknowledgments. The current observations were performed by the staff of John A. Lambie, County Engineer, Los Angeles County, under the direction of E. T. Mankey, Division Engineer, Survey Division.

I wish to express my thanks to my co-workers in the Geodetic Section of the Survey Division for their assistance in making the necessary analysis and adjustments upon which this paper is based. 


\section{REFERENCES}

Berbower, R. F., Subsidence problem in the Long Beach harbor district, J. Waterways and Harbors Div., Proc. Am. Soc. Civil Engrs., 85, WWQ, June 1959.

Bowie, W., Earth movements in California, U. S. Coast and Geodetic Survey Spec. Publ. 106, Washington, D. C., 1924.

Bowie, W., Comparison of old and new triangulation in California, U.S. Coast and Geodetic Survey Spec. Publ. 151, Washington, D. C., 1928.

Gilluly, J., and U. S. Grant, Subsidence in the Long Beach harbor area, California, Bull. Geol. Soc. Am., 60, 461-529, 1949.

Hayford, J. F., and A. L. Baldwin, The earth movements in the California earthquake of $1906, R e-$ port of the Superintendent, US.C.\&GS., Appendix 3, pp. 67-104, 1907.

Hayes, S. A., Report on earth movement measurements in the Baldwin Hills, unpublished reports,
Los Angeles Dept. of Water and Power, 1943, 1947, 1951, 1955, and 1959.

Kobold, F., Measurements of displacement and deformation by geodetic methods, J. Surv. and Mapping Div., Proc. Am. Soc. Civil Engrs., 87, $S U$ Q, July 1961 .

Whitten, C. A., Horizontal earth movement in California. The Journal, Coast and Geodetic Survey, no. 2, April 1949.

Whitten, C. A., Horizontal movement in the earth's crust, J. Geophys. Research, 65, 2839$2844,1960$.

(Manuscript received February 5, 1962; revised March 5, 1962. Presented at the Symposium on Geodetic Determination of Earth Movements in California, held during the First Western National Meeting of the American Geophysical Union, at the University of California, Los Angeles, California, on December 28, 1961.) 